\title{
Goal Post Injuries in Soccer
}

\section{A Laboratory and Field Testing Analysis of a Preventive Intervention}

\author{
David H. Janda, ${ }^{\star} \dagger$ MD, Cynthia Bir, ${ }^{\star} \ddagger$ MS, RN, Bart Wild, ${ }^{*}$ Steve Olson, $\S$ and \\ Robert N. Hensinger, | MD
}

From *The Institute for Preventative Sports Medicine and Orthopedic Surgery Associates,
$\ddagger$ Catherine McAuley Health Systems, and Departments of §Recreational Sports and
$\|$ Pediatric Orthopedic Surgery, University of Michigan, Ann Arbor, Michigan

\section{ABSTRACT}

Soccer is the most popular team sport worldwide, with approximately 40 million amateur participants. Most fatalities in soccer are related to player impact with the goal post. This study focuses on two case reports, a laboratory testing phase, and a pilot field testing phase of preventive equipment that can be used around the goal to prevent injury. Horizontal and vertical impact testing in the laboratory revealed impact force was diminished when the goal post was covered with protective padding (reduction of $31 \%$ and $63 \%)(P<0.05)$. These data showed a statistically significant decrease in force at all temperatures. In the pilot field testing phase of the study, 471 games were monitored. Soccer teams participating in youth, teen, and adult soccer leagues were included in this phase of the study. During the 3-year study, there were seven player collisions with padded goal posts, and no injuries were recorded. The use of padded goal posts within the game of soccer has been documented to reduce the possibility of injury, both in the laboratory phase and in the pilot field testing phase.

Soccer is the most popular team sport worldwide, with an estimated 40 million amateur participants. ${ }^{4}$ In addition, soccer is the fastest growing team sport in the United States. ${ }^{6}$ The US Consumer Product Safety Commission ${ }^{7}$ has determined through the National Electronic Injury Surveillance System that between 1989 and 1992, 647,368 soccer injuries were treated at emergency departments in

† Address correspondence and reprint requests to: David $H$. Janda, $M D$ Institute for Preventative Sports Medicine, PO Box 7032, Ann Arbor, MI 48107.

No author or related institution has received any financial benefit from research in this study. See "Acknowledgments" for funding information. the United States. It should be noted that this figure is an underestimation of the actual number of injuries occurring nationwide since this figure does not include physician office visits. The distribution of the injuries, as determined by the Consumer Product Safety Commission, reveals 71\% of the injuries were sustained by male players and $29 \%$ by female players. Ankle injuries account for $19.2 \%$ of all soccer injuries; knee injuries, $12.7 \%$; head and facial injuries, $11.3 \%$; lower leg injuries, $7.8 \%$, and foot injuries, $7.5 \%$. In a previous study, ${ }^{5}$ a rate of 3.7 injuries was found per 1000 hours of soccer per player for male participants between the ages of 12 to 18 years.

Eighteen percent of all soccer injuries occur to the goalkeeper. ${ }^{7}$ It should be noted that goalkeepers make up only $6 \%$ of the total soccer population. It is therefore evident that an inordinate percentage of injuries are occurring to the person playing the position of goalkeeper. Over a 13year period, the Consumer Product Safety Commission has identified 18 individuals who died after impacts with the goal post. This particular cause of fatal injury is the most common in soccer. The common scenario for these fatalities is the goal post falling on top of the child. Thus it would appear that the area in and around the goal is the most dangerous for serious injury. However, if the goal posts are to be made stationary to prevent tip over fatalities, the number of impact injuries could increase since an immovable object is being placed on the field of play. It has been suggested that padding stationary goal posts is a viable option to eliminate the risk of goal post injuries in soccer. To date, no laboratory or field testing of various types of padding systems has been reported in the literature. The purpose of this study is to present laboratory and clinical experience with padded goal posts for preventing head injury in soccer.

\section{CASE STUDIES}

Two case studies are presented involving impact with a goal post. The injuries illustrated in the case studies involve a 
movable goal post system falling on top of a player. It has been previously proposed that a removable goal post system would reduce and possibly eliminate injuries in the sport of soccer. The case studies illustrate the necessity of a more stationary and secure type of goal post system.

\section{Case 1}

A 10-year-old boy was struck by a goal that was blown over by wind. He sustained a $\mathrm{C} 4-5$ fracture dislocation. At the time of the injury the patient was neurologically intact with the exception of a C5 radiculopathy. The patient was placed in halo traction. A magnetic resonance imaging scan revealed no evidence of cord compression. The patient underwent a posterior cervical fusion of C3 through C5 with posterior wiring and an iliac crest bone graft, and a decompression of the fifth cervical nerve root. He remained in the halo immobilizer for 8 weeks. His C5 radiculopathy findings have cleared, and he is currently asymptomatic.

\section{Case 2}

An 11-year-old boy was standing near a soccer goal post when some other children picked up the goal and tipped it over on him. The patient was struck on the head and lost consciousness. Both lower extremities were pinned beneath the cross bar of the goal.

The patient regained consciousness and was examined at a local hospital where he was transferred to a tertiary referral center. In addition to his closed head injury, he had a Salter III condylar fracture of the left distal femur and a right distal femoral shaft fracture. The patient was placed in right-balanced skeletal traction and a left long leg cylinder cast. After 6 weeks of skeletal traction, the patient was placed in a right hip spica cast for 2 months. Physical therapy was required for the patient to regain range of motion and strength of the lower extremities.

At last followup, he had full range of motion in both knees and hips and was pain free. However, the patient has had difficulty related to his closed head injury. He has had difficulties with short-term memory, a short attention span, behavioral difficulties, and falling grades at school, none of which were present before his injury. The patient is currently being treated with a closed head injury protocol.

\section{LABORATORY TESTING PHASE}

\section{Horizontal impact testing apparatus}

A horizontal impact apparatus was used in this study (Fig. 1). This testing unit consists of a 16 foot long horizontal track rigidly mounted with a $1.27-\mathrm{cm}$ diameter steel guide extending the full length of the track. The carriage assembly has four sets of roller bearing units mounted at a $45^{\circ}$ angle, allowing the carriage to have nearly friction free horizontal movement along the steel guide. A Greenco Cable-trol cylinder (Greenco Cable-trol, Tampa, FL) was used to accelerate the carriage assembly. The nylon-coated steel cable attached to the piston of the cylinder has a trolley block that fits into the bottom side of the carriage

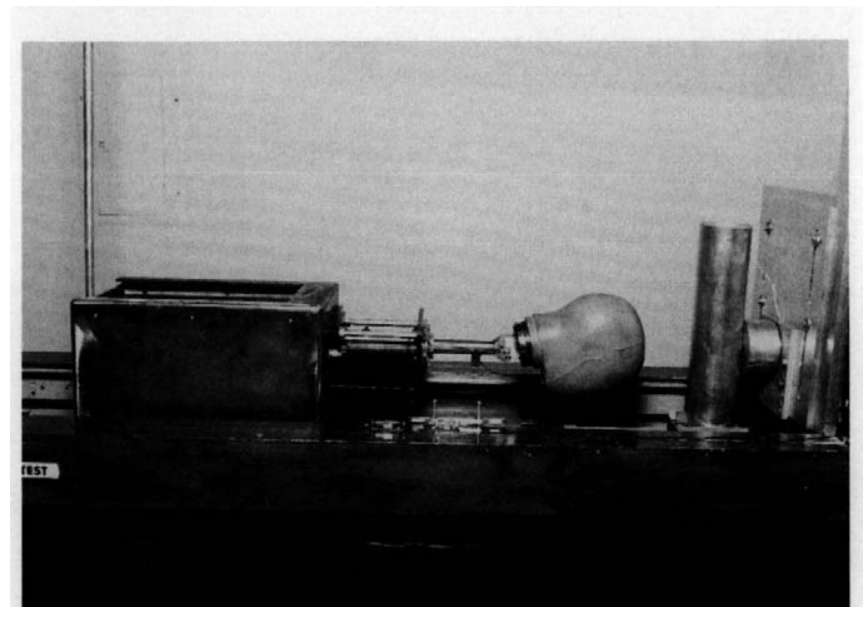

Figure 1. Horizontal impact testing machine used to test goal posts and padding in the laboratory setting.

assembly and propels the assembly down the track. A central control panel allows for the selection of six adjustable electrical solenoid valves located on the exhaust ports of the air cylinder system. A charge tank allows for the entire system to be charged to a desired pressure before a specific trial. By changing the amount of pressure within the cylinder system and selecting a combination of the solenoid valves, the velocity of the assembly can be regulated.

The carriage assembly consists of a steel box measuring $45 \times 30 \times 25 \mathrm{~cm}$ and weighing approximately 65 pounds. This box is used to simulate a person's body and weight can be added or subtracted to obtain the desired body weight. A Humanoid head form (Wayne State University, Detroit, MI) is mounted to a steel rod approximately $2.5 \mathrm{~cm}$ in diameter that is then attached to the steel box. The entire carriage system, without added weight, is 85 pounds. This system better simulates a person colliding with a goal post than the standard head-neck-trolley system because the body weight is also simulated.

This machine accelerates the carriage and Humanoid head form along the steel track until an impact occurs with an instrumented anvil at the end of the track. A load cell within the anvil is used to measure the force of the impact. The acceleration (deceleration) of the Humanoid head form is measured near its center of gravity. The velocity of the carriage system is measured just before impact using a mechanical trigger system.

The Humanoid head form was developed and validated at Wayne State University, Detroit, Michigan, for use in impact testing of the head. ${ }^{1}$ The National Operating Committee on Standards for Athletic Equipment (NOCSAE) has developed standards for headgear used in athletic events based on tests performed with this head form.

\section{Goal posts tested}

A baseline test was performed using both square and round aluminum goal posts without any type of protective covering. Then, 11 different types of goal post pads were applied to the bare goal posts (Fig. 2). These pads were within the following four groups: 


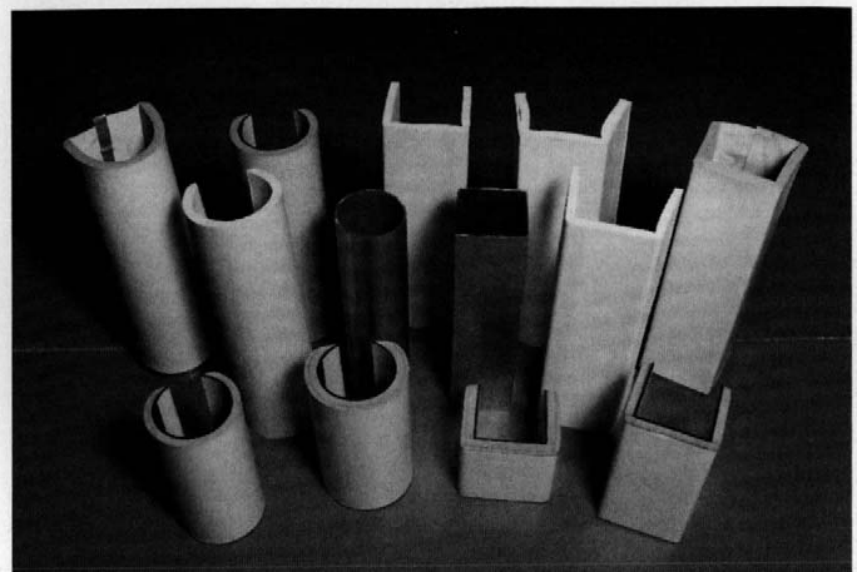

Figure 2. The 11 types of goal post pads that were tested on both the horizontal and vertical impact machines.

Group 1 (Vinyl Nitrate + Skin $[\mathrm{VN}+\mathrm{S}]$, Round and Square; $N=2$ ): These pads were fabricated from $1.25-\mathrm{cm}$ thick, closed cell vinyl nitrile foam, 71-pound density, which includes an outer vinyl skin that was $0.05 \mathrm{~cm}$ thick.

Group 2 (Minicell polyethylene [MCP] and Minicell polyethylene + Skin [MCP+S], Round and Square; $N=4$ ): These pads were molded into round and square shapes from sheets of 3- to 4-pound minicell polyethylene. Pads were tested with and without an outer vinyl skin.

Group 3 ( A and C [1.25 cm thick] and B and D [1.88 cm thick]; $N=4$ ): These pads were fabricated from closed cell vinyl nitrile foam, 71-pound density, with the outer vinyl skin and a $0.95 \mathrm{~cm}$ ABS (acrylic, butyl rubber, and styrene) inner core.

Group 4 (VN+S Round-Weathered; $N=1$ ): These pads were fabricated from $1.25-\mathrm{cm}$ thick closed cell vinyl nitrile foam, 71-pound density, with the outer vinyl skin. They were exposed to the natural elements for 2 years.

\section{Testing matrix}

Since a standard for testing goal posts is nonexistent, each goal post pad was evaluated using head impact testing methods. The head-neck-trolley system (vertical impact apparatus) specified in the National Operating Committee on Standards for Athletic Equipment (NOCSAE) standards for helmet testing was used as one testing method and the horizontal impact apparatus provided a second means of testing. In both methods, the load of the impact and the acceleration at the center of gravity of the head form were measured and recorded.

The first tests were performed with the head-necktrolley system (Fig. 3). The goal posts were placed on an anvil firmly attached to the base plate of the testing unit. A drop height of approximately 6 inches was established to obtain an impact velocity of $1.07 \mathrm{~m} / \mathrm{s}$.

The horizontal impact apparatus was then used to test each goal post. The posts were placed directly in front of the anvil containing the load cell. The carriage system was then accelerated to obtain the same impact velocity of 1.07 $\mathrm{m} / \mathrm{s}$, which was accomplished by pressurizing the system to

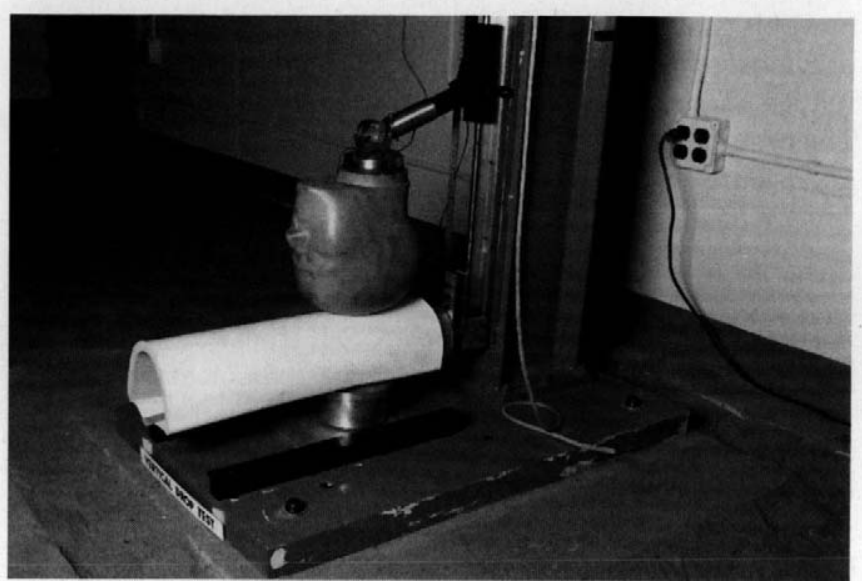

Figure 3. Vertical impact testing machine used to test goal posts and padding in the laboratory setting.

24 psi and opening the first solenoid valve. In both tests, impacts occurred directly to the parietal region of the head form and were transferred to the center of gravity of the head form where the accelerometer was located.

Five impacts were performed on each goal post and pad combination at each of the following temperatures: $0^{\circ} \mathrm{C}$, $12.4^{\circ} \mathrm{C}$, and $38^{\circ} \mathrm{C}$. These represent the extreme and normal temperatures encountered during the play of soccer. After each impact for the controls (no pad), a new goal post was used to avoid any discrimination cause by the first impacts such as deformation of the post.

\section{Biomechanical responses}

From the center of gravity of the Humanoid head form, accelerations were recorded. The total load transferred from the head form through the goal post was recorded by the load cell located in the anvil. A 486 computer with an A-to-D conversion board (RC Electronics, Goletta, CA) and software served as the data acquisition system to record these responses. The sampling rate was $5000 \mathrm{~Hz}$. Three channels of data were collected, with the third channel being the velocity obtained by the mechanical trigger system. Maximum impact loads were also calculated using the load cell data.

\section{PILOT FIELD PHASE OF STUDY}

The Ann Arbor and Saline, Michigan, communities participated in this phase of the study. Four soccer fields in Saline and two soccer fields in Ann Arbor were equipped with the padded goal posts. The padding used was the $\mathrm{VN}+\mathrm{S}$ prototype as described in the laboratory phase portion. The soccer teams, participating in youth, teen, and adult soccer leagues, played their games on fields equipped with the padded posts between 1991 and 1993. Supervisors on each field documented collisions with the goal posts, rebounds of the ball on impact with the goal post, and reaction of the players, coaches, fans, and referees. An injury was defined as any event that required the game being stopped or the player having to be removed from play. Additionally, it was considered an injury when anyone missed 
a subsequent practice or game. A total of 471 games were monitored between 1991 and 1993 in this manner.

\section{RESULTS OF LABORATORY TESTING PHASE}

Horizontal and vertical impact results

Our data revealed the $B$ and $D$ padding to be the best for force reduction at all temperatures in both the horizontal (reduction of $31 \%$ to $41 \%$ compared with no pad) and vertical (reduction of $55 \%$ to $63 \%$ ) impacts (Table 1 ). The $\mathrm{VN}+\mathrm{S}$ pad reduced the force of impact at all temperatures between $27 \%$ and $34 \%$ in horizontal impact testing and $40 \%$ and $51 \%$ in vertical impact testing. These values were statistically significant when compared with the control of no pad $(P<0.05)$. However, there was no statistically significant difference between the $\mathrm{VN}+\mathrm{S}$ and $\mathrm{B}$ and $\mathrm{D}$ pads. These findings are also demonstrated in Figures 4 and 5.

Without padding, the goal post forces generated were higher with square posts, both on the horizontal and vertical impacts (Table 2). With padding present, the square posts reduced the force of impact more than the round posts; however, not to a statistically significant level. Without the padding, the square goal posts were observed to deform slightly, but the round posts did not appear to be affected. Both the square and round posts did not appear to be affected when tested with pads in place.

With all factors considered, the $B$ and $D$ padding, followed by the $\mathrm{VN}+\mathrm{S}$, demonstrated the greatest reduction in the force of impacts both horizontally and vertically. The shape of the goal posts and the variance in temperatures did not have a statistically significant effect on these results.

After 2 years of weathering, the $\mathrm{VN}+\mathrm{S}$ padding continued to significantly reduce the horizontal impact force (Table 3) (Fig. 6). There was no statistically significant difference between the new pads tested and the pads that had been weathered. The structural properties of the pads remained unchanged as well.

Larger forces were generated with the horizontal impacts than with the vertical impacts (Table 4). The addition of body weight in the horizontal testing could more closely represent impacts occurring on the field.

TABLE 1

Average load cell results of horizontal and vertical goal post impacts with varying temperatures

\begin{tabular}{lccc}
\hline $\begin{array}{c}\text { Padding } \\
\text { type }\end{array}$ & $\begin{array}{c}\text { Cold } \\
0^{\circ} \mathrm{C} \\
(\mathrm{N})\end{array}$ & $\begin{array}{c}\text { Room } \\
124^{\circ} \mathrm{C} \\
(\mathrm{N})\end{array}$ & $\begin{array}{c}\text { Hot } \\
38^{\circ} \mathrm{C} \\
(\mathrm{N})\end{array}$ \\
\hline $\begin{array}{l}\text { Horizontal impacts } \\
\text { A and C }\end{array}$ & 3911.0 & 4244.6 & 4483.4 \\
B and D & 3067.9 & 3748.2 & 3663.7 \\
MCP & 4472.6 & 4323.9 & 4539.8 \\
No pad & 5210.7 & 5589.0 & 5284.2 \\
VN+S & 3463.0 & 3962.6 & 3840.3 \\
Vertical impacts & & & \\
A and C & 2909.9 & 2969.7 & 3201.1 \\
B and D & 1970.2 & 1964.7 & 2176.2 \\
MCP & 3106.3 & 3162.7 & 3178.6 \\
No pad & 5258.7 & 5091.8 & 4886.0 \\
VN+S & 2564.4 & 2856.4 & 2955.8 \\
\hline
\end{tabular}

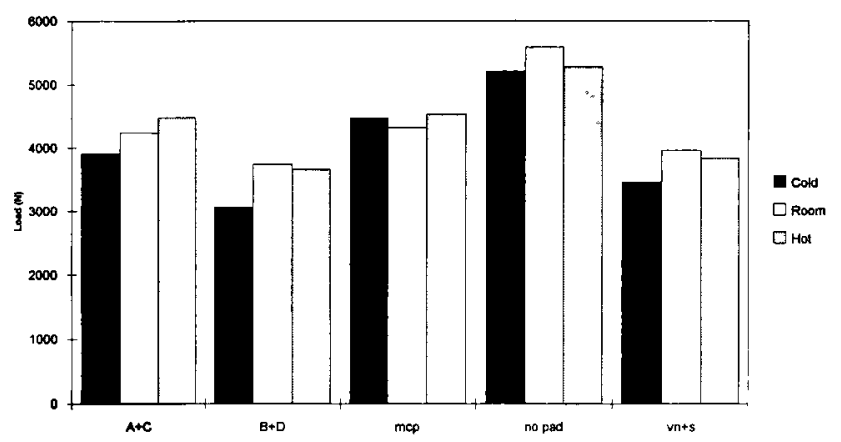

Figure 4. Average load values with varying temperatures on horizontal impacts. Cold, $0^{\circ} \mathrm{C}$; Room, $12.4^{\circ} \mathrm{C}$; Hot, $38^{\circ} \mathrm{C}$.

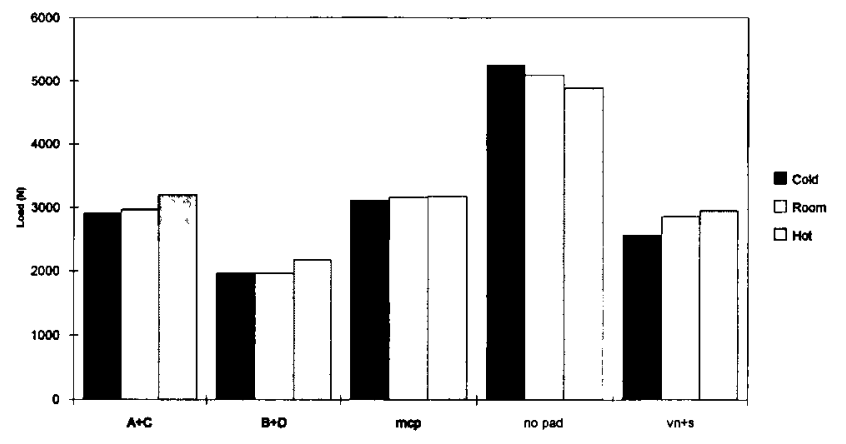

Figure 5. Average load values with varying temperatures on vertical impacts. Cold, $0^{\circ} \mathrm{C}$; Room, $12.4^{\circ} \mathrm{C}$; Hot, $38^{\circ} \mathrm{C}$. See text for explanation of the padding types.

TABLE 2

Average load cell results of horizontal and vertical goal post impact with varying goal post shapes

\begin{tabular}{lcc}
\hline \multicolumn{1}{c}{ Padding type } & $\begin{array}{c}\text { Round } \\
(\mathrm{N})\end{array}$ & $\begin{array}{c}\text { Square } \\
(\mathrm{N})\end{array}$ \\
\hline Horizontal impacts & & \\
A and C & 4542.4 & 3883.6 \\
B and D & 3616.4 & 3370.2 \\
MCP & 4633.8 & 4257.0 \\
No pad & 5314.2 & 5408.4 \\
VN+S & 3744.5 & 3766.0 \\
Vertical impacts & & \\
A and C & 3538.8 & 2515.0 \\
B and D & 2388.8 & 1685.3 \\
MCP & 3289.2 & 3009.2 \\
No pad & 4666.7 & 5491.0 \\
VN+S & 2998.3 & 2586.0 \\
\hline
\end{tabular}

\section{RESULTS OF THE PILOT FIELD PHASE OF THE STUDY}

During the 471 soccer games monitored between 1991 and 1993,7 collisions of players and posts were documented. Of these seven collisions, no injuries were sustained. It should be noted that the supervisors who monitored the field, in addition to documenting the number of injuries, documented the reactions of the officials, players, coaches, and spectators. None of these groups criticized the posts and, in fact, most did not realize that the posts had any padding. In addition, the field supervisors monitored the rebound 
TABLE 3

Average load values for horizontal goal post impacts of old and new goal post pads with varying temperatures

\begin{tabular}{lcc}
\hline \multicolumn{1}{c}{ Temperature } & $\begin{array}{c}\text { Old } \\
(\mathrm{N})\end{array}$ & $\begin{array}{c}\text { New } \\
(\mathrm{N})\end{array}$ \\
\hline Cold $\left(0^{\circ} \mathrm{C}\right)$ & 3524.0 & 3170.0 \\
Hot $\left(38^{\circ} \mathrm{C}\right)$ & 4506.4 & 4112.6 \\
Room $\left(12.4^{\circ} \mathrm{C}\right)$ & 4259.1 & 4040.5 \\
\hline
\end{tabular}

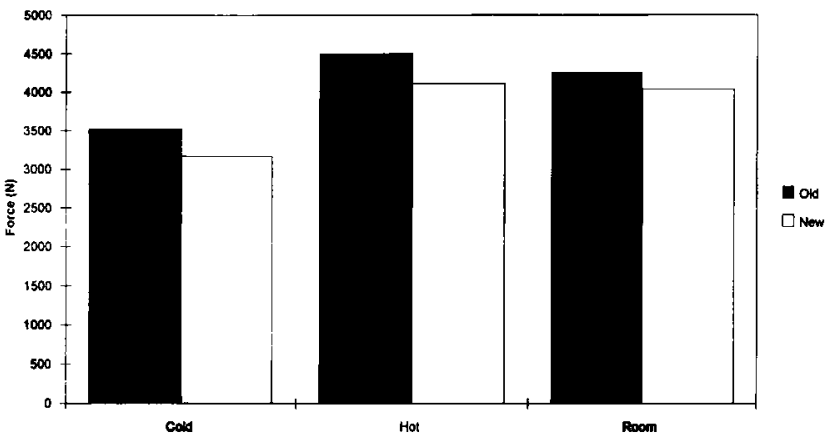

Figure 6. Old versus new goal post pads at varying temperatures; pads were weathered over a period of 2 years. Cold, $0^{\circ} \mathrm{C}$; Hot, $38^{\circ} \mathrm{C}$; Room, $12.4^{\circ} \mathrm{C}$.

TABLE 4

Average load cell results of horizontal and vertical goal post impacts with all factors considered

\begin{tabular}{lcc}
\hline $\begin{array}{c}\text { Padding } \\
\text { type }\end{array}$ & $\begin{array}{c}\text { Horizontal } \\
(\mathrm{N})\end{array}$ & $\begin{array}{c}\text { Vertical } \\
(\mathrm{N})\end{array}$ \\
\hline A and C & 4213.0 & 3026.9 \\
B and D & 3493.3 & 2037.1 \\
MCP & 4445.4 & 3149.2 \\
No pad & 5361.3 & 5078.8 \\
VN+S & 3755.3 & 2792.2 \\
\hline
\end{tabular}

characteristics of the soccer balls after impact with the goal posts and found that there were no adverse effects in reference to the rebound of the ball off the post.

\section{DISCUSSION}

Soccer has been gaining popularity in the United States over the past decade. This increase in participation level of the general public can be attributed to a general interest in the sport itself, the impression by the general public that soccer is safer than other sports, and the arrival of the World Cup to the United States in 1994. The majority of soccer injuries can be classified as impact injuries. These impact injuries occur as player versus player, ball versus player, and player versus goal post. It has been documented by the Consumer Product Safety Commission that most fatal injuries in soccer are related to goal post-player impacts. The case reports presented in this study illustrate the injuries that can occur with a removable soccer goal post. Stationary goal posts also carry a potential for impact injury. When a player collides with the post, the post remains static; therefore, the player must absorb all of the energy from impact. In this study, the use of padding on the stationary goal posts was found to be effective in absorbing some of this impact energy. Therefore, the laboratory portion of this study, as well as the prospective field portion, supports the concept that modifying the goal posts can alter the pattern and frequency of injuries in soccer.

In the laboratory portion of the study, it was evident that the prototypes tested at all temperatures absorbed impact forces at a significantly higher level than the standard control goal posts. The prospective field testing portion of the study illustrated that no injuries were documented during a 3 -year period. No complaints were logged with the field supervisors regarding the implementation of this passive preventive measure.

This study is yet another example of the effect of a preventive approach within the field of sports medicine. Previous measures implemented in recreational softball and baseball have yielded a significant reduction in injuries and related health care costs. The use of breakaway bases, another form of a passive preventive intervention, resulted in a $96 \%$ reduction in injuries and a $99 \%$ reduction in health care costs. ${ }^{2}$ An actuarial analysis performed by the Centers for Disease Control on the data from that study revealed that if all fields in the United States were switched to breakaway bases, 1.7 million injuries per year would be prevented, resulting in a savings of $\$ 2.0$ billion per year in short-term health care costs. ${ }^{3}$ The use of padding systems on stationary goal posts in soccer should have an effect similar to that of breakaway bases used in softball and baseball: a reduction in injuries without altering the flow or enjoyment of the game and the added benefit of a potential reduction in associated health care costs.

\section{ACKNOWLEDGMENTS}

The authors express their appreciation to Catherine $\mathrm{McAu}$ ley Health System for funding the laboratory portion of this study. In addition, thanks must go to Mr. John Marcello and Danmar Products for their help in developing the goal post padding materials used in this study. The Ann Arbor and Saline soccer communities must also be thanked as well as Barb and Ken Sturms and Ms. Jackie Rowe. The authors thank Mr. Robert Perino for his help with the laboratory setup and maintenance of the testing equipment.

\section{REFERENCES}

1. Hodgson VR, Mason MW, Thomas LM: Head model for impact. The Sixteenth Stapp Car Crash Conference-Proceedings. New York, SAE, Inc 1972 (SAE No. 720969), pp 1-13

2. Janda $D H$, Wojtys $E M$, Hankin FM, et al: Softball sliding injuries. A prospective study comparing standard and modified bases. JAMA 259: $1848-$ 1850,1988

3. Janda DH, Wojtys EM, Hankin FM, et al: Softball sliding injuries-Michigan, 1986-1987. MMWR 37: 169-70, 1988

4. Maehulm S, Daljord OA: Football injuries in Oslo: A one year study. $\mathrm{Br}$ $J$ Sports Med 8: 186-190, 1984

5. Schmidt-Olsen S, Jørgensen U, Kaalund $S$, et al: Injuries among young soccer players. Am J Sports Med 19: 273-275, 1991

6. Sullivan JA, Gross RH, Grana WA, et al: Evaluation of injuries in youth soccer. Am J Sports Med 8: 325-327, 1980

7. United States Consumer Product Safety Commission summary reports National Electronic Injury Surveillance-System: 1990 through 1992. Washington, DC, US Consumer Product Safety Commission, 1993 